\title{
A QUANTITATIVE STUDY OF THE EFFECT OF AN ALKYLATING AGENT (TRIETHYLENEMELAMINE) ON THE SEMINIFEROUS EPITHELIUM OF RATS
}

\author{
E. STEINBERGER* \\ Division of Endocrinology, Department of Internal Medicine, Wayne State University \\ and Detroit Receiving Hospital, Detroit, Michigan, U.S.A. \\ (Received 26th Fune 1961)
}

\begin{abstract}
Summary. The testicular germinal epithelium in rats treated with triethylenemelamine (TEM) was subjected to a quantitative analysis. The analysis revealed that TEM, at a dose level of $0.2 \mathrm{mg} / \mathrm{kg}$, has a specific effect on the early generations of Type A spermatogonia. The disappearance of the more mature type of cells was shown to be largely due to a maturation-depletion process. A minimal effect on the primary spermatocytes was observed after repeated administration of TEM. Evidence was presented that this could be a result of a cumulative action of the drug. In no instance, however, was an effect observed on the synchronicity of the spermatogenic process. The data support the hypothesis that the response of the germinal epithelium to noxious stimuli is a precisely defined process confined to one or more types of the germinal epithelium cells.
\end{abstract}

\section{INTRODUCTION}

Voluminous literature concerning biological and biochemical effects of alkylating agents has accumulated in the past two decades. A striking resemblance was observed between the effects of alkylating agents and ionizing radiation (Powers \& Pomeroy, 1958; Alexander \& Stacey, 1958). This has led to the introduction of the term 'radiomimetic' as a reference to alkylating agents. In vitro studies suggest that both alkylating agents and ionizing radiation have an adverse effect on DNA molecules (Stacey, Cobb, Cousins \& Alexander, 1958). Morphologic changes in cultures of tissue exposed to alkylating agents are qualitatively similar to those induced by ionizing radiation (Cobb, 1960). The effect of triethylenemelamine (TEM) on reproduction of the male rat partly resembles that of ionizing radiation, and is characterized by damage to the spermatogonia followed by maturation depletion of the germinal epithelium (Steinberger, Nelson, Boccabella \& Dixon, 1959). Recently, Oakberg (1955), employing a quantitative method of analysis, defined with precision the morphologic changes in the germinal epithelium that are produced by ionizing radiation. He has shown that moderate doses of ionizing radiation specifically damage Type $B$, late Type $A$ and intermediate spermatogonia, but permit the more mature germinal cells to continue their development.

\footnotetext{
* National Science Foundation Postdoctoral Fellow. Present address: Korman Research Building,
} Albert Einstein Medical Centre, York and Tabor Roads, Philadelphia, Pa., U.S.A. 
We have utilized a quantitative method of analysis of the germinal epithelium described by Leblond \& Clermont (1952) to define with precision the changes that take place following systematic administration of TEM. Application of this method of evaluation permits a direct comparison of the effects of TEM and ionizing radiation on the seminiferous epithelium and provides significant information concerning the effects of alkylating agents on actively growing cells.

\section{MATERIALS AND METHODS}

Adult (220 to $250 \mathrm{~g}$ ) male hooded rats were injected intraperitoneally with $0.2 \mathrm{mg}$ TEM per $\mathrm{kg}$ body weight, daily for 5 days. Groups of animals (four to eight) were sacrificed at various intervals after initiation of treatment. An additional group of six males received a single injection of $0.2 \mathrm{mg} / \mathrm{kg}$ TEM and was sacrificed 5 days later.

Following paraffin embedding, the testes were sectioned at 3 to $4 \mu$ and stained by the PAs-haematoxylin technique. Sections of testes from each animal were examined microscopically and a qualitative assessment of the germinal epithelium was made. One testis from each group of experimental animals and two testes from intact adult control animals were prepared for quantitative study. Classification and identification of the various cell types and stages of the 'cycle of seminiferous epithelium' was conducted by the method described by Leblond \& Clermont (1952) and Clermont \& Morgentaler (1955). For this purpose, a stained histological preparation of a cross-section taken from the centre of the testis was photographed. Each tubule in the photograph was identified by microscopic examination of the respective tissue section and its stage noted. Cross-sections of tubules in Stages I, II, V, VII and XIV were examined in detail. Counts of the resting, zygotene, transitional and pachytene primary spermatocytes, Type A (including intermediate) and B spermatogonia were performed on all cross-sections of tubules that happened to be in one of the above mentioned stages of spermatogenesis.

\section{RESULTS}

Histological changes in the testes of rats treated for 5 days with $0 \cdot 2 \mathrm{mg} / \mathrm{kg}$ TEM have been described for periods starting 11 days after initiation of treatment (Steinberger et al., 1959). These changes consisted in disappearance of spermatogonia followed by a maturation depletion of the remaining germinal epithelium. Histological examination at earlier intervals obtained in the present study revealed an apparent decrease of spermatogonia. This, however, was difficult to assess on the basis of a qualitative microscopic examination.

EFFECT OF TEM TREATMENT ON THE FREQUENCY OF OCCURRENCE OF THE VARIOUS STAGES OF THE 'CYCLE OF SEMINIFEROUS EPITHELIUM'

It has been demonstrated that in any given cross-section of a tubule of a normal rat testis the germinal epithelial cells form a definite 'cellular association'. Such 'associations' follow each other in temporal fashion to produce the 'cycle of the seminiferous epithelium'. The proportion of tubules in a particular stage 
('cellular association') of the cycle is constant in different testicular crosssections of the same testis as well as of testes from different rats (Leblond \& Clermont, 1952).

The frequency of stages (expressed in percentages) of the 'cycle of seminiferous epithelium' in animals treated with TEM is summarized in Table 1. The results are based on studies of testicular sections from animals sacrificed at periods of 2 to 34 days after initiation of a 5-day treatment.

TABLE 1

EFFEGT OF TEM ON FREQUENCY OF OCGURRENCE OF THE VARIOUS STAGES OF THE 'CYCLE OF SEMINIFEROUS EPITHELIUM'

\begin{tabular}{|c|c|c|c|c|c|c|c|c|c|}
\hline \multirow{2}{*}{$\begin{array}{l}\text { Stage of } \\
\text { cycle }\end{array}$} & \multirow{2}{*}{$\begin{array}{c}\text { Intact } \\
\text { controls }\end{array}$} & \multicolumn{8}{|c|}{ No. days after initiation of treatment } \\
\hline & & 2 & 4 & 10 & 12 & 14 & 21 & 28 & 34 \\
\hline I & $12 \cdot 2$ & $11 \cdot 4$ & $17 \cdot 5$ & $11 \cdot 3$ & 11.9 & $12 \cdot 7$ & $5 \cdot 1$ & $7 \cdot 8$ & 7.0 \\
\hline II-III & 12.6 & 13.5 & 10.6 & 16.2 & 14.2 & $5 \cdot 3$ & $10 \cdot 8$ & 7.9 & $10 \cdot 1$ \\
\hline IV & $4 \cdot 9$ & $4 \cdot 7$ & $4 \cdot 4$ & $2 \cdot 7$ & 3.9 & $3 \cdot 3$ & $3 \cdot 3$ & $4 \cdot 2$ & $3 \cdot 8$ \\
\hline V & $3 \cdot 6$ & $3 \cdot 4$ & $3 \cdot 2$ & $4 \cdot 3$ & $3 \cdot 7$ & $4 \cdot 6$ & $2 \cdot 7$ & $3 \cdot 7$ & $3 \cdot 3$ \\
\hline VI & $8 \cdot 2$ & $5 \cdot 9$ & $4 \cdot 4$ & $4 \cdot 3$ & $3 \cdot 0$ & $6 \cdot 4$ & $6 \cdot 8$ & $3 \cdot 4$ & $5 \cdot 4$ \\
\hline VII-VIII & $28 \cdot 3$ & $31 \cdot 2$ & $26 \cdot 6$ & $29 \cdot 1$ & $33 \cdot 2$ & $31 \cdot 1$ & $29 \cdot 2$ & $30 \cdot 3$ & 31.5 \\
\hline IX & $4 \cdot 6$ & $4 \cdot 2$ & $4 \cdot 9$ & $3 \cdot 2$ & $3 \cdot 3$ & $3 \cdot 5$ & $4 \cdot 6$ & $5 \cdot 6$ & $3 \cdot 5$ \\
\hline $\mathrm{X}$ & $3 \cdot 0$ & $2 \cdot 4$ & 1.9 & $2 \cdot 4$ & $3 \cdot 0$ & $2 \cdot 7$ & $2 \cdot 4$ & $1 \cdot 6$ & $3 \cdot 2$ \\
\hline XI & $3 \cdot 4$ & $4 \cdot 4$ & $3 \cdot 6$ & $3 \cdot 2$ & $4 \cdot 2$ & $3 \cdot 7$ & $3 \cdot 5$ & $3 \cdot 4$ & $4 \cdot 0$ \\
\hline XII-XIII & $16 \cdot 7$ & $15 \cdot 3$ & $17 \cdot 1$ & $18 \cdot 1$ & 14.9 & $17 \cdot 1$ & $14 \cdot 1$ & $10 \cdot 9$ & 11.9 \\
\hline XIV & $3 \cdot 3$ & $3 \cdot 4$ & $5 \cdot 9$ & $5 \cdot 4$ & $4 \cdot 5$ & $5 \cdot 0$ & 0.4 & $9 \cdot 1$ & $5 \cdot 5$ \\
\hline $\begin{array}{l}\text { Un- } \\
\text { determined }\end{array}$ & 0 & 0 & 0 & 0 & 0 & 5 & $16 \cdot 5$ & $12 \cdot 2$ & $10 \cdot 6$ \\
\hline $\begin{array}{l}\text { No. } \\
\text { tubules } \\
\text { counted }\end{array}$ & 1134 & 614 & 527 & 371 & 666 & 481 & 450 & 623 & 632 \\
\hline
\end{tabular}

Up to the 12th day, the stages were easily identified in all tubules; starting with the 14th day, however, severe derangement of the germinal epithelium in some of the tubules interfered with the process of identification. Examination of the data shows no departure of the per-cent frequency distribution of the various stages from control values of intact rats, at time intervals up to the 12th day. A certain amount of variation was encountered after the 12th day in Stages I, II to III, VI, X, XIV, and was probably due to the fact that a number of tubules could not be properly identified and had to be classified as undetermined.

\section{Spermatogonia}

EFFEGT OF TEM ON COUNTS OF GERMINAL EPITHELIUM GELLS

Tubules in Stages I, II, V, VII and XIV were analysed. The number of spermatogonia was determined in each cross-section of a tubule that happened to be in one of the above stages. The arithmetic means of the counts and the standard deviations of the means are presented in Table 2.

Counts from untreated animals agree closely with those obtained for normal animals by Clermont \& Leblond (1953). In the experimental animals, a marked change was observed $48 \mathrm{hr}$ after the first injection. Tubules in Stages I, and XIV showed a decreased number of Type A spermatogonia (less than one 
per cross-section). However, tubules in Stages II, V and VII showed only a slight decrease. The Type B spermatogonia, counted in tubules in Stage V remained unchanged. Four days after initiation of treatment, a marked decrease of Type A spermatogonia was observed in tubules in Stage II; Type B spermatogonia, however, showed essentially no change. Ten days after initiation of treatment, the number of Type A spermatogonia began to increase in tubules in Stages XIV and II while Type B spermatogonia showed a marked drop from the normal of nineteen to 1.4 per cross-section. The counts of all

TABLE 2

EFFECT OF FIVE DAILY DOSES OF TEM ON THE NUMBER OF SPERMATOGONIA PER CROSSSECTION OF A SEMINIFEROUS TUBULE

\begin{tabular}{|c|c|c|c|c|c|c|}
\hline \multirow{2}{*}{$\begin{array}{l}\text { Days after } \\
\text { initiation } \\
\text { of treatment }\end{array}$} & \multicolumn{3}{|c|}{ Type A spermatogonia } & \multicolumn{2}{|c|}{$\begin{array}{c}\text { Type } A \text { and intermediate } \\
\text { spermatogonia }\end{array}$} & \multirow{2}{*}{$\frac{\begin{array}{c}\text { Type B } \\
\text { spermatogonia }\end{array}}{\text { Stage } V}$} \\
\hline & Stage $V$ & Stage VII & Stage XIV & Stage I & Stage II & \\
\hline 2 & $1.9 \pm 0 \cdot 2^{*}$ & $1 \cdot 4+0 \cdot 1$ & $0.9 \pm 0.2$ & $1 \cdot 1 \pm 0 \cdot 02$ & $6 \cdot 0 \pm 1 \cdot 0$ & $22 \cdot 9 \pm 1 \cdot 6$ \\
\hline 4 & $1 \cdot 4 \pm 0 \cdot 1$ & $1 \cdot 2 \pm 0 \cdot 1$ & $0 \cdot 7 \pm 0 \cdot 1$ & $0.4 \pm 0.07$ & $0 \cdot 7 \pm 0 \cdot 2$ & $16 \cdot 4 \pm 1 \cdot 4$ \\
\hline 10 & $1 \cdot 2 \pm 0 \cdot 3$ & $1 \cdot 1 \pm 0 \cdot 1$ & $1 \cdot 6 \pm 0 \cdot 1$ & - & $1.9 \pm 0 \cdot 2$ & $1 \cdot 4 \pm 0.5$ \\
\hline 12 & $1 \cdot 2 \pm 0 \cdot 2$ & $0 \cdot 7 \pm 0 \cdot 1$ & $1 \cdot 1 \pm 0 \cdot 1$ & 一 & $2 \cdot 4 \pm 0 \cdot 2$ & $2 \cdot 4 \pm 0 \cdot 5$ \\
\hline 14 & $1 \cdot 4 \pm 0 \cdot 2$ & $1 \cdot 0 \pm 0 \cdot 1$ & $0 \cdot 8 \pm 0 \cdot 2$ & - & $3 \cdot 2 \pm 0 \cdot 7$ & $5 \cdot 0 \pm 0 \cdot 8$ \\
\hline 21 & $1 \cdot 4 \pm 0 \cdot 2$ & $1 \cdot 5 \pm 0 \cdot 1$ & $1 \cdot 4 \pm 0 \cdot 1$ & - & $4 \cdot 0 \pm 0 \cdot 5$ & $4 \cdot 4 \pm 0 \cdot 4$ \\
\hline 28 & $3 \cdot 6 \pm 0 \cdot 5$ & $1 \cdot 8 \pm 0 \cdot 1$ & $3 \cdot 2 \pm 0 \cdot 2$ & - & $9 \cdot 0 \pm 0 \cdot 9$ & $19 \cdot 0 \pm 0 \cdot 2$ \\
\hline 34 & $3 \cdot 5 \pm 0 \cdot 6$ & $2 \cdot 6 \pm 0 \cdot 2$ & $3 \cdot 3 \pm 0.01$ & - & $7 \cdot 7 \pm 0 \cdot 4$ & $25 \cdot 4 \pm 1 \cdot 6$ \\
\hline No. treatment & $2 \cdot 8 \pm 0 \cdot 3$ & $1 \cdot 9 \pm 0 \cdot 2$ & $3 \cdot 8 \pm 0 \cdot 2$ & $6 \cdot 8 \pm 0 \cdot 6$ & $8 \cdot 6 \pm 0 \cdot 6$ & $19 \cdot 2 \pm 0 \cdot 1$ \\
\hline $\begin{array}{l}\text { Mean number } \\
\text { of cross- } \\
\text { sections } \\
\text { analysed } \\
\text { per testicle }\end{array}$ & 18 & 84 & 25 & 70 & 29 & 18 \\
\hline
\end{tabular}

$*$ Mean \pm s.E.

types of spermatogonia remained depressed on the 12th and 14th days; however, by the 21 st day a definite increase of Type A spermatogonia in tubules in Stages XIV and II was observed. Type B spermatogonia showed a slight increase. By the 28th day, both Type A and Type B spermatogonia returned to normal levels. Similar results were obtained on the 34th day.

\section{Primary spermatocytes}

The counts of the resting (Stage VII), zygotene (Stage XIV), transitional (Stages I, II, III) and pachytene (Stage VII) primary spermatocytes are summarized in Table 3.

No significant change could be observed 2 and 4 days after initiation of treatment. There was, however, a slight drop in pachytene and resting spermatocytes on the 4th day, and on the 10th day a further decrease in the numbers of 
pachytene and transitional (Stages II and V) spermatocytes was observed. The resting spermatocytes, however, showed the most dramatic change (normals $44 \cdot 0 \pm 1.0$, vs. experimental $1.0 \pm 0.3$ ). On the 12 th day, an abrupt drop to zero of zygotene (Stage XIV) spermatocytes was observed. On the 14th day, only pachytene spermatocytes in tubules in Stage $\mathrm{V}$ were present in significant numbers; all others had diminished, essentially, to zero. On Day 21 , a definite recovery of resting spermatocytes took place, while the transitional

TABLE 3

EFFECT OF FIVE DAILY DOSES OF TEM ON THE NUMBER OF PRIMARY SPERMATOCYTES PER CROSS-SECTION OF A SEMINIFEROUS TUBULE

\begin{tabular}{|c|c|c|c|c|c|c|}
\hline \multirow{2}{*}{$\begin{array}{l}\text { Days after } \\
\text { initiation of } \\
\text { treatment }\end{array}$} & \multirow{2}{*}{$\frac{\text { Resting }}{\text { Stage VII }}$} & \multirow{2}{*}{$\frac{\text { Zygotene }}{\text { Stage XIV }}$} & \multicolumn{2}{|c|}{ Transitional } & \multicolumn{2}{|c|}{ Pachytene } \\
\hline & & & Stage I & Stage II & Stage $V$ & Stage VII \\
\hline 2 & $41 \cdot 7 \pm 1 \cdot 2^{*}$ & $42.4 \pm 0.9$ & $49 \cdot 1 \pm 2 \cdot 4$ & $50 \cdot 0 \pm 1 \cdot 5$ & $52 \cdot 1 \pm 1 \cdot 4$ & $57 \cdot 8 \pm 0 \cdot 6$ \\
\hline 4 & $38 \cdot 3 \pm 1 \cdot 4$ & $50 \cdot 0 \pm 2 \cdot 8$ & $54 \cdot 2 \pm 1 \cdot 6$ & $51 \cdot 5 \pm 1 \cdot 3$ & $53 \cdot 1 \pm 2 \cdot 0$ & $51 \cdot 0 \pm 2 \cdot 1$ \\
\hline 10 & $1 \cdot 0 \pm 0 \cdot 3$ & $39 \cdot 4 \pm 0 \cdot 6$ & - & $16 \cdot 6 \pm 2 \cdot 1$ & $33 \cdot 0 \pm 0.4$ & $36 \cdot 1 \pm 1 \cdot 3$ \\
\hline 12 & $3 \cdot 3 \pm 0 \cdot 4$ & 0.0 & - & $20 \cdot 5 \pm 2 \cdot 4$ & $16 \cdot 0 \pm 2 \cdot 8$ & $5 \cdot 8 \pm 1 \cdot 2$ \\
\hline 14 & $2 \cdot 8 \pm 0 \cdot 1$ & 0.0 & - & $2 \cdot 2 \pm 1 \cdot 3$ & $18 \cdot 4 \pm 2 \cdot 6$ & $0 \cdot 6 \pm 0.3$ \\
\hline 21 & $10 \cdot 3 \pm 1 \cdot 1$ & 0.0 & - & 0.0 & 0.0 & 0.0 \\
\hline 28 & $27 \cdot 7 \pm 1 \cdot 1$ & $9 \cdot 9 \pm 0 \cdot 4$ & - & $28 \cdot 8 \pm 0 \cdot 4$ & $21 \cdot 0 \pm 1 \cdot 1$ & $6 \cdot 5 \pm 0.5$ \\
\hline 34 & $47 \cdot 3 \pm 1 \cdot 3$ & $57 \cdot 5 \pm 2 \cdot 0$ & - & $48 \cdot 1 \pm 3 \cdot 1$ & $10 \cdot 0 \pm 2 \cdot 0$ & $16 \cdot 7 \pm 1.5$ \\
\hline No. treatment & $44 \cdot 0 \pm 1 \cdot 0$ & $49 \cdot 0 \pm 1 \cdot 8$ & $50 \cdot 0 \pm 1 \cdot 3$ & $58 \cdot 0 \pm 1 \cdot 1$ & $54 \cdot 5 \pm 1 \cdot 4$ & $69 \cdot 0 \pm 1 \cdot 3$ \\
\hline $\begin{array}{l}\text { Mean number } \\
\text { of cross- } \\
\text { sections } \\
\text { analysed } \\
\text { per testicle }\end{array}$ & 84 & 25 & 70 & 29 & 18 & 84 \\
\hline
\end{tabular}

* Mean \pm S.E.

spermatocytes in Stage $\mathrm{V}$ diminished to zero. All types of primary spermatocytes were present in testes of rats sacrificed on the 28th day. By the 34th day, recovery was well under way, the numbers of resting and zygotene primary spermatocytes having returned to normal and transitional spermatocytes in Stage II approaching the normal values. Pachytene spermatocytes in Stages V and VII, although having definitely increased in numbers, remained well below the normal. By the 67 th day, recovery of the germinal epithelium was complete in all tubules.

Effect of a single dose of TEM

Results of the counts are summarized in Table 4. It is evident that Type A spermatogonia were effected in all analysed tubules. Type B spermatogonia and resting spermatocytes showed a very slight drop and pachytene, transitional, and zygotene spermatocytes showed no change. 


\section{DISCUSSION}

Histological studies of the germinal epithelium of testes from rats treated with high doses of TEM revealed that TEM, a 'radiomimetic compound', affects spermatogonia specifically, (Steinberger et al., 1959). The observed changes were qualitatively similar to those produced by X-irradiation (Shaver, 1949; Steinberger \& Nelson, 1957). Recent studies of the mouse testes, with quantitative techniques for analysis of the germinal epithelium, revealed differential sensitivity of the various types of spermatogonia towards ionizing radiation.

\section{TABLE 4}

EFFECT OF A SINGLE DOSE (0/2 MG/KG) OF TEM ON THE NUMBER OF GERMINAL GELLS PER CROSS-SEGTION OF A SEMINIFEROUS TUBULE; ANIMALS SAGRIFICED 5 DAYS AFTER THE INJECTION

\begin{tabular}{|c|c|c|c|c|}
\hline Cell type & Stage & Normal & TEM treated & $\begin{array}{l}\text { No. cross- } \\
\text { sections analysed } \\
\text { per testicle }\end{array}$ \\
\hline A & $\mathrm{V}$ & $2 \cdot 8 \pm 0 \cdot 3^{*}$ & $1 \cdot 1 \pm 0 \cdot 2$ & 21 \\
\hline A & VII & $1 \cdot 9 \pm 0 \cdot 2$ & $1 \cdot 2 \pm 0 \cdot 1$ & 25 \\
\hline A & XIV & $3 \cdot 8 \pm 0 \cdot 18$ & $0 \cdot 8 \pm 0 \cdot 2$ & 30 \\
\hline$A$ and In. & I & $6 \cdot 8 \pm 0 \cdot 6$ & $1 \cdot 2 \pm 0 \cdot 1$ & 84 \\
\hline$A$ and In. & II & $8 \cdot 6 \pm 0.6$ & $2 \cdot 8 \pm 0 \cdot 2$ & 39 \\
\hline B & V & $19 \cdot 2 \pm 0 \cdot 1$ & $18 \cdot 3 \pm 1 \cdot 3$ & 22 \\
\hline $\mathbf{R}$ & VII & $44 \cdot 0 \pm 1 \cdot 0$ & $32 \cdot 0 \pm 1 \cdot 1$ & 23 \\
\hline$Z$ & XIV & $49 \cdot 0 \pm 1 \cdot 8$ & $53 \cdot 0 \pm 3 \cdot 0$ & 30 \\
\hline $\mathrm{T}$ & I & $50 \cdot 0 \pm 1 \cdot 3$ & $50 \cdot 6 \pm 1 \cdot 4$ & 28 \\
\hline $\mathrm{T}$ & II & $58 \cdot 0 \pm 1 \cdot 1$ & $53 \cdot 2 \pm 2 \cdot 4$ & 11 \\
\hline $\mathbf{P}$ & $\mathrm{V}$ & $54 \cdot 5 \pm 1 \cdot 4$ & $50 \cdot 0 \pm 3 \cdot 3$ & 20 \\
\hline $\mathbf{P}$ & VII & $69 \cdot 0 \pm 1 \cdot 3$ & $58 \cdot 9 \pm 1 \cdot 6$ & 25 \\
\hline
\end{tabular}

A-Type A spermatogonia B-Type B spermatogonia P-Pachytene spermatocytes $\mathrm{Z}$-Zygotene spermatocytes

$$
\begin{aligned}
& \text { In. - Intermediate spermatogonia } \\
& \mathbf{R} \text { - Resting primary spermatocytes } \\
& \mathbf{T} \text { - Transitional spermatocytes } \\
& * \text { - Mean } \pm \text { s.e. }
\end{aligned}
$$

The intermediate and Type B spermatogonia were destroyed, while a large percentage of early Type A spermatogonia survived and apparently were responsible for regeneration of the seminiferous epithelium during the recovery period. The primary spermatocytes were relatively resistant to ionizing radiation, although large doses affected the early pachytene stages and prevented the normal process of maturation division (Oakberg, 1955). Although it had been demonstrated that TEM chiefly affects spermatogonia, in order to fulfil the requirements of a 'radiomimetic' compound, at least as far as its effect on spermatogenesis is concerned, the spermatogonia should show a differential sensitivity towards TEM similar to that exhibited towards ionizing radiation. 
Recently, Clermont, Leblond \& Messier (1959), employing radioactive tracers, have shown that in the rat the process of spermatogenesis requires 48 days. Since spermatogenesis comprises four 'cycles of seminiferous epithelium', an estimate of 12 days for each 'cycle' can be made. Knowing the frequency distribution of the various stages of the 'cycle', it is possible to calculate the duration of each stage (see Table 5). The knowledge of the duration of each stage combined with the ability to identify with precision each type of cell in the germinal epithelium (Leblond \& Clermont, 1952) permits an accurate calculation of the

\section{TABLE 5}

DURATION OF STAGES OF THE 'GYGLE OF THE SEMINIFEROUS EPITHELIUM' (THE FREQUENCY DISTRIBUTION OF VARIOUS STAGES ADAPTED FROM GLERMONT, LEBLOND \& MESSIER, 1959)

\begin{tabular}{c|c|c|c|c|c|c|c|c|c|c|c|c}
\hline Stage & $I$ & $I I$ & $I I I$ & $I V$ & $V$ & $V I$ & $V I I$ & $V I I I$ & $\begin{array}{c}I X, \\
X I\end{array}$ & $X I I$ & $X I I I$ & $X I V$ \\
\hline $\begin{array}{c}\text { Frequency } \\
(\%)\end{array}$ & $12 \cdot 1$ & $8 \cdot 1$ & $2 \cdot 1$ & $4 \cdot 5$ & $5 \cdot 1$ & $9 \cdot 2$ & $21 \cdot 8$ & $7 \cdot 4$ & $7 \cdot 5$ & $11 \cdot 2$ & $6 \cdot 1$ & 4.9 \\
\hline $\begin{array}{c}\text { Duration } \\
(\mathrm{hr})\end{array}$ & $34 \cdot 9$ & $23 \cdot 3$ & $6 \cdot 0$ & $13 \cdot 0$ & $14 \cdot 7$ & $26 \cdot 5$ & $62 \cdot 8$ & $21 \cdot 3$ & $20 \cdot 6$ & $32 \cdot 3$ & $17 \cdot 6$ & $14 \cdot 1$ \\
\hline
\end{tabular}

expected number of any cell type in a given cross-section of a seminiferous tubule. A departure from the expected number and the temporal pattern of such a change can be used to localize the site of cellular damage to the germinal epithelium.

The data reported in this paper show that, $48 \mathrm{hr}$ after initiation of TEM treatment, a decrease occurs of Type A spermatogonia, from a normal of 3.8 and 6.8 to 0.9 and 1.1 per cross-section in tubules in Stages XIV and I, respectively. Other types of germinal epithelium cells, including Type $\mathrm{A}$ and intermediate spermatogonia in Stage II and Type B spermatogonia in Stage V, remained morphologically intact at this time interval. Normally, in Stages V through VIII there is only one Type A spermatogonium to be found per crosssection of the seminiferous tubule. The number increases progressively following mitotic divisions in Stages IX, XII, I, III and V (Leblond \& Clermont, 1952). Thus, theoretically there should be four Type A spermatogonia in Stage XIV and eight in a cross-section of a tubule in Stage I (the actual numbers in our control animals were 3.8 and $6 \cdot 8$, respectively). In treated animals, the number was about one per cross-section in Stages XIV and I. In Stage II, however, the number of Type A spermatogonia in the same time interval was essentially unchanged. The drastic drop in the number of spermatogonia in Stages XIV and I could be explained in two ways. First, one might assume that TEM affects all spermatogonia produced after the first mitosis in Stage IX, but not those produced by the third mitotic division in Stage I. Secondly, it is possible that TEM affects the spermatogonia in a specific stage of their early development (somewhere between Stages IX and I) and the observed drop in the number of spermatogonia in Stages XIV and I is due to a process of maturation depletion. The first assumption does not seem to be 
plausible because, if TEM had produced an immediate and direct effect on spermatogonia in Stages XIV and I, there should have been, $48 \mathrm{hr}$ after initiation of treatment, a drop in the number of spermatogonia in Stage II and possibly Type $B$ spermatogonia in Stage $V$, due to maturation depletion. This follows because it takes about $43.3 \mathrm{hr}$ for the spermatogonia in tubules in Stage II to become Type B spermatogonia in Stage V (see Table 5). On the other hand, if the second assumption is correct, the decline in spermatogonia in Stages XIV and I was due to a maturation-depletion process, secondary to damage produced to spermatogonia that must have been in Stages XI or XII $48 \mathrm{hr}$ earlier or at the onset of treatment (see Table 5). Since spermatogonia in Stage II were essentially intact at the 48 -hr interval, their precursors must have escaped the effect of TEM. Thus spermatogonia in and beyond Stage XIII at the onset of treatment (see Table 5) were probably resistant to TEM. Since it is known that the first spermatogonial division occurs in Stage IX, and the second in Stage XII tubules one may conclude that TEM probably affects the first spermatogonial generation and possibly the younger members of the second generation. The sequential loss of more mature types of cells at later time intervals (i.e. Type A and intermediate spermatogonia from tubules in Stage II, 4 days, and Type B spermatogonia, 10 days, after initiation of treatments - see Tables 2 and 3) was probably due to a process of maturation depletion.

Since the animals in the series of experiments discussed above received five daily injections of TEM, the possibility should be considered that the drop in Type A spermatogonia in tubules in Stage II, 5 days after initiation of treatment, was due to an accumulative effect of the drug rather than to maturation depletion. This possibility was checked by giving a group of animals a single dose of тем and sacrificing them 5 days after the injection. Analysis of the germinal epithelium revealed a depletion of Type A spermatogonia in Stages XIV, I and II but no changes of Type B spermatogonia in Stage V. Since Type B spermatogonia were essentially intact $(120 \mathrm{hr}$ after the injection), their precursors on the day of injection (Type A spermatogonia in Stage XII) could not have been affected by TEM. This suggests that the effect of TEM on spermatogonia was not cumulative and specifically affected the first and possibly the early second generations of Type A spermatogonia.

The pattern of the depletion of primary spermatocytes confirms further the assumption that TEM destroys specifically the early Type A spermatogonia only. A marked drop in the number of the youngest primary spermatocytes (resting primary spermatocytes) was first observed in animals sacrificed 10 days after the initiation of treatment, a time related to the earlier depletion of the most mature spermatogonia. A decrease in numbers of the more mature spermatocytes took place in an orderly and predictable time sequence thereafter except for an irregularity 4 days after initiation of treatment. The pachytene primary spermatocytes showed a definite decrease in numbers and became depleted considerably earlier than could be explained by an orderly maturationdepletion process. A cumulative effect of TEM on the pachytene primary spermatocytes producing an early asynchronous drop in their numbers is a possible explanation for this irregularity. This hypothesis is supported by the 
experiment showing a lack of a drop in the number of pachytene spermatocytes 5 days after a single injection of TEM.

The recovery pattern of primary spermatocytes also follows a chronological order, the resting spermatocytes showing signs of recovery earliest, and returning essentially to normal levels about 2 weeks after the time of complete depletion.

Although TEM similarly to X-irradiation affects specifically the spermatogonia the pattern of damage is different. Whereas X-irradiation affects mainly Type $\mathrm{B}$, intermediate and some Type A spermatogonia (Oakberg, 1955), the effect of TEM in the doses employed in our study appears to be limited to the early generations of Type A spermatogonia. This difference in the site of action between TEM and ionizing radiation may indicate that the mechanism of TEM effect on the germinal epithelium is different from that of ionizing radiation. For this reason, the term 'radiomimetic' may not be suitable, at least in reference to the effect of TEM on the germinal epithelium. However, the possibility that the discussed differences between the effect of ionizing radiation and TEM are due to a species difference (Oakberg using mice, our experiments done on rats) should be kept in mind.

The data reported in this paper show that the morphologic effect of TEM on the rat testes is confined to a specific generation of the Type A spermatogonia only. This finding supports the hypothesis advanced by Steinberger \& Dixon (1960) that the response of the germinal epithelium to noxious agents is not necessarily a non-specific reaction as suggested by Payne (1957), but can be a precisely defined response of a specific type of the germinal epithelial cells to the damaging agent.

\section{ACKNOWLEDGMENT}

This study was supported in part by a grant from the Population Council, Inc.

\section{REFERENCES}

Alexander, P. \& Stacey, K. A. (1958) Comparison of the changes produced by ionizing radiation and by the alkylating agents: evidence for a similar mechanism at the molecular level. Ann. N.Y. Acad. Sci. 68, 1225.

Clermont, Y. \& Leblond, C. P. (1953) Renewal of spermatogonia in the rat. Amer. 7. Anat. 93, 475.

Clermont, Y., Leblond, G. P. \& Messier, B. (1959) Durée du cycle de l'épithélium séminal du rat. Arch. Anat. micr. Morph. exp. 48, 37.

Clermont, Y. \& Morgentaler, H. (1955) Quantitative study of spermatogenesis in the hypophysectomized rat. Endocrinology, 57, 369 .

Совв, J. P. (1960) The comparative cytological effects of several alkylating agents on human normal and neoplastic cells in tissue culture. Ann. N.r. Acad. Sci. 84, 513.

Leblond, C. P. \& Clermont, Y. (1952) Spermiogenesis of rat, mouse, hamster and guinea pig as revealed by the 'periodic acid-fuchsin sulfurous acid' technique. Amer. F. Anat. 90, 167.

OAkBeRG, E. F. (1955) Degeneration of spermatogonia of the mouse following exposure to X-rays, and stages in the mitotic cycle at which cell death occurs. 7 . Morphol. $97,39$.

PAYNe, J. M. (1956) The degenerative changes in the adult mouse testis returned to the abdominal cavity. 7. Path. Bact. 71, 117.

Powers, E. L. \& Pomeroy, J. H. (1958) Comparison of the biological effects of ionizing radiations and certain alkylating agents in cell systems. Ann. N.Y. Acad. Sci. 68, 702.

Shaver, S. L. (1953) X-irradiation injury and repair in the germinal epithelium of male rats. I. Injury and repair in adult rats. Amer. F. Anat. 92, 391. 
Stacey, K. A., Сobb, M., Cousens, S. F. \& Alexander, P. (1958) The reactions of the 'radiomimetic' alkylating agents with macromolecules in vitro. Ann. N.Y. Acad. Sci. 68, 682.

Steinberger, E. \& Dixon, W. J. (1959) Some observations on the effect of heat on the testicular germinal epithelium. Fertil. \& Steril. 10, 578.

Steinberger, E. \& Nelson, W. O. (1957) Effect of furadroxyl treatment and X-irradiation on the hyaluronidase concentration of rat testis. Endocrinology. 60, 105.

Steinberger, E., Nelson, W. O., Boccabella, A. \& Dixon, W. J. (1959) A radiomimetic effect of triethylenemelamine on reproduction in the male rat. Endocrinology, 65, 40. 